\title{
Inclusive education and its place in the interactive information space
}

\author{
Andrey Shevchenko ${ }^{1}$, Margarita Beglaryan $^{21 *}$, and Elena Pichkurenko ${ }^{3}$ \\ ${ }^{1}$ North Caucasus Branch of the Russian State University of Justice, 350047, Krasnodar, Russia \\ ${ }^{2}$ North Caucasus Branch of the Russian State University of Justice, 350047, Krasnodar, Russia \\ ${ }^{3}$ Kuban State University, 350040, Krasnodar, Russia
}

\begin{abstract}
The significance of the research is determined by the evolution of social structure of the society as a response to the challenges of our time, to the IT development process and the transition to a new formation information society. The information society provides particular individuals with a wide range of opportunities for personal development and inclusion into the socio-communicative environment. People with disabilities get a chance to be included into general process of knowledge acquiring. The innovation of the approach consists in the comprehension of inclusive education in a social and philosophical vein. The goal of the article is the estimation of the opportunities and the relevance of such approach for the society and the youth. The global scale of isolation of people as a way of defense against the virus makes our research more relevant, since now many are forced to receive educational services only via the Internet, using remote methods, when the inclusion of people with developmental disabilities in this process becomes even more natural and organic.
\end{abstract}

\section{Inclusive education and its social and communication support}

One of the priorities in the modern world is providing equal opportunities of social and personal formation for all people. Traditionally the distribution of social benefits is realized in the process of competitive procedure and it immediately results from the difference in the personal features of society members. This process of the competitive procedure has been confessed one of the natural mechanisms of self-organization of social fabric. However, for people whose development opportunities are initially limited due to health disorders the situation is ambiguous. In circumstances when the system of education is not adapted for the peculiarities of participation of children with disabilities in the educational process their condition is invariably losing that contradicts the idea of equal opportunity provided by the state. The aim of the article is a theoretical working of problems and perspectives of the inclusive education, its place in the interactive information space. Comparative study to the handlings of the problem of children's with disabilities education both in Russian society and other countries is given. Positive and negative sides of the inclusive education as one of the

1* Corresponding author: rita_beg@mail.ru 
most advanced models of integrating children with disabilities into the educational process are observed. The conducted analysis shows not only the moment of expediency of the inclusive education, but the problem of factors of efficiency of its implementation. It is being proved that without observing some terms vague measures for integrating children with disabilities into the educational process can lead to the destructive consequences. In conclusion the question of necessity of application of systemic approach in the performance of reforms connected with the introduction of the inclusive education with due account for modern technological and informational- technical opportunities of society and wish of its use is observed.

The problem of inclusive education in the Russian society has been investigated relatively recently. It is due to the fact that in the Soviet period there was a formed paradigm of the attitude to children with disabilities as objects of wardship as a result of which there was the realization of mechanisms of isolation of children with disabilities from healthy children in the framework of activities of some special institutions - foster homes. After the Soviet Union breakup the series of hard social disruptions predetermined rather low degree of actualization of the problem of upbringing of children with disabilities. The majority of Russian publications on this topic dates back to 2000-2010. At the same time in the West there exists an active process of development of the problem of inclusive education which is realized not only on the level of pedagogic and psychological theory, but on the level of analysis of practical results of the first attempts of the realization of the model of the inclusive education. The given publishing was based on the thesis research of such domestic publications as Ziatdinova G.R. [1], Chigrina A.Y. [2], Medovaya N.A. [3] devoted to the problems of socialization of disabled children and perspectives of the inclusive education and articles of such authors as Buravleva N.A, Gritzkevich N.K., Iglovskaya N.V. [4], Kurmisheva L.K. [5], Goneyev A.D., Samartzeva E.G [6] devoted to the analysis of the model of the inclusive education itself and its institutional aspects and foreign experience. Also researches on the problem of the inclusive education conducted by such foreign authors as Guralnick M.J., Connor R.T., Hammond M.A., Gottman J.M., Kinnish K. [7], Kavale K., Forness S. [8], Dyson A. [9], Park R. [10], Thomas G., Walker P., Webb J. [11], Wright E.B. [12] have been put to the basis of this work.

As one of the most important aspects of school life is the realization of conflict models of interaction between schoolchildren (that can result in serious psychological damages for disabled children) the observation of the phenomenon of bulling based on the works of such authors as Petrosyantz V.R. [13,14], Sizova I.L. [15] has been done. The following foreign authors paid serious attention to the problem of bulling: Batsche G.M., Knoff H.M. [16], Berthold K. A., Hoover, J. H. [17], Besag V. E. [18], Dodge K.A. [19], Dodge K.A., Crick N.R. [20].

The works of such foreign authors as Bell R.Q. [21], EriksonE.H. [22], Gardner H. [23], Karnes M.B. [24], Maccoby E.E. [25], Stanley, S.F. [26] are devoted to the problems of common and child socialization.

\section{Social modeling of inclusive education}

The empiric base of the research was the survey of the students of the higher education institutions of Krasnodar. The goal of the survey: to study the opinions of students about the education of persons with disabilities in mass school (high school).

The survey method allowed defining not only the students' opinion, but their attitude to the fact they would study with the persons having diversities as well. The survey was developed with the goal to gain diverse material for the theme: from the comprehending the inclusive approach to the personal attitude and participating in such process. 
In two higher educational institutions of Krasnodar (North Caucasian branch of FSBEIHE "Russian State University of Justice" and Kuban Socio- Economical Institute) there have been conducted a survey participants of which were the students of law faculty and students of economical and technical branches. 282 people were asked among who 219 are the students of law faculty, 35 persons get technical professions and 28 -economical ones.

The aim of the survey: the study of students' opinions on the question of education of people with disabilities in mass school (high school).

Students were given opportunity to make a complete answer to one question:

1. How do you understand "inclusive education"?

The rest of the questions were formulated in such a way that answers correspond to the scale: $(+)$ estimate positively; $( \pm)$ - estimate positively, but mark some disadvantages; $(\mathrm{m})$ estimate negatively, but mark some advantages; $(-)$ - negatively on the whole; $(0)$ - not sureldon't know. The rest of the questions related to the personal data of the interviewees.

Here are given the questions of the survey:

1. Do you consider it appropriate to train people with developmental disabilities in a mass school (institute)?

2. How do you feel about the existence of inclusive education?

3. Do you consider the level of creation and implementation of conditions for the training of persons with disabilities at the university sufficient?

4. How do you rate the tutor's work?

5. How would you rate the degree of development of inclusive education in our country?

6. Indicate your gender.

7. Indicate your specialty (direction).

8. Indicate your course of study.

The results of the conducted survey were processed with the use of statistical methods.

So, we put forward the aim: study the attitude of young people to the inclusive education, estimate the understanding of the importance of this question among young people, elicit response or refusal, get social mandate or message what to do or improve in scientific, pedagogic, philosophic and social terms for the inclusive education to become useful for people with disabilities and not to become the cause of wrong and negative attitude in the modern world both on the part of young people and on the part of parents.

At the initial stage, a factor analysis method was applied to the questionnaire results, which allowed one to distinguish aggregate variables. As the source data for factor analysis, the answers to questions 1-5 were used. At the second stage, the relationships of the selected factors with additional variables were analyzed, which allows us to get an idea of what values of factor variables are most pronounced in a particular group.

To identify the main factors responsible for the attitude of the respondents to inclusive education, factor analysis of the maximum likelihood method was used.

The purpose of the first step of the method is to identify the optimal number of factors. We identified two factors that affect the results of the survey (Table 1). When answering questions 1-2, respondents expressed their attitude to inclusive education. Thus, the first factor can be described as "Attitude". The second factor is closely related to questions 3-5, in which the respondents noted the development of inclusive education and its components. Conventionally, a factor can be designated as "Development".

Table 1. Eigenvalues.

\begin{tabular}{|c|c|c|c|}
\hline Value & Eigenvalue & The percentage of total variance & Cumulative percentage \\
\hline Factor 1 & 3.50 & 26.86 & 26.86 \\
\hline Factor 2 & 2.36 & 19.30 & 46.16 \\
\hline
\end{tabular}

Analyzing the data of table 1 , it can be noted that, the percentage of variance attributable to the first general factor was 26.86 ; the second factor is 19,30 . The total percentage of 
variance, explained by all factors, is 46.16 . At the next step of the study, we used the rotation method, where the procedure for extracting the main components is similar to a rotation that maximizes the variance (varimax method) of the original variable space. For example, in a scatter chart, you can view the regression line as the $\mathrm{X}$ axis by rotating it so that it coincides with the direct regression. Since the criterion (goal) of rotation is to maximize the variance (variability) of the "new" variable (factor) and minimize the spread around it "varimax" of the initial data, which allows us to distinguish the factor structure and variables marked by high values of the correlation coefficients with one or another factor . The correlation was considered strong if its coefficient took a value of more than 0.70 (Table 2).

Table 2. Factor loadings.

\begin{tabular}{|c|c|c|}
\hline Variable & Factor 1 & Factor 2 \\
\hline Question 1 & 0,76 & \\
\hline Question 2 & 0,88 & \\
\hline Question 3 & & 0,91 \\
\hline Question 4 & & 0,74 \\
\hline Question 5 & & 0,88 \\
\hline
\end{tabular}

Analysis of table 2 shows that the first factor includes two variables with positive values of the correlation coefficient. The weight of factor 1, "Ratio," was $26.86 \%$. From a substantive point of view, the result suggests that the degree of attitude towards inclusive education is correlated. The weight of factor 2 "Development" was $19.30 \%$.

In addition to questions revealing attitudes towards inclusive education, the questionnaire contained additional information regarding the respondent's gender and year of study. The next step in the analysis was to find the relationship between the obtained factors and additional variables.

To solve this problem, contingency tables and a chi-square test were used to test the hypothesis of independence of signs. The factor values of the first and second factors were divided into 4 groups, as a result of which two new factor variables were obtained (we denote them by $\mathrm{p} 1$ and $\mathrm{p} 2$ ) containing values from 1 to 4 . For the first factor, a value of 1 corresponds to the position "I evaluate as a whole positively"; value 2 - position "I evaluate positively, but note shortcomings"; value 3 - position "I evaluate negatively, but note a number of advantages"; value 4 - the position is "generally negative." For the second factor, the values are similar. Using the contingency table tool of STATISTICA 6.0. a joint distribution of such variables as gender_p1, education_p1, training_p1, gender_p2, education_p2, training_p2 was obtained, which served as the initial data for calculating the chi-square criterion and, in addition, allowed us to analyze what values of the factor variables $\mathrm{p} 1$ and $\mathrm{p} 2$ most pronounced for each group.

The use of the chi-square criterion made it possible to test the hypothesis of independence of attributes gender_p1, education_p1, training_p1, gender_p2, education_p2, training_p2. As an example, we give two contingency tables that reflect the distribution of variables gender_p1 and training_p1, gender_p2 and training_p2 (tables 3-4).

Table 3. Contingency table (sex_p1).

\begin{tabular}{|c|c|c|c|c|c|}
\hline & \multicolumn{4}{|c|}{$\begin{array}{c}\text { P1 (Factor 1) } \\
\text { Pearson's Chi Square: } 4,2 ; \mathrm{p}=0,23, \alpha=0,05\end{array}$} & \multirow[b]{2}{*}{ Total } \\
\hline Gender & $\begin{array}{c}1 \\
\text { «overall } \\
\text { positive»» }\end{array}$ & $\begin{array}{c}2 \\
\text { «I appreciate it, but } \\
\text { note the flaws» }\end{array}$ & $\begin{array}{c}3 \\
\text { «I assess it negatively, } \\
\text { but note a number of } \\
\text { advantages» }\end{array}$ & $\begin{array}{c}4 \\
\text { «overall } \\
\text { negative» }\end{array}$ & \\
\hline 1 & 18 & 62 & 50 & 20 & 150 \\
\hline 2 & 11 & 46 & 48 & 27 & 132 \\
\hline Total & 29 & 108 & 98 & 47 & 282 \\
\hline
\end{tabular}


An analysis of Table 3 shows that in the whole sample, the 2 nd value ("I assess it positively, but note deficiencies") of the factor variable p1 is most pronounced (38\% of respondents). Among the male respondents, the most frequently present options are "I evaluate positively, but note shortcomings" or "I evaluate negatively, but note a number of advantages" (Table 3), both occur at approximately the same frequency. Among female respondents, the value "I assess positively, but note shortcomings" is more pronounced (Table 3). However, the chi-square test indicates a slight difference in the level of relationship depending on gender $(\mathrm{p}=0.23>\alpha=0.05)$

Table 4. Contingency table (course_p1).

\begin{tabular}{|c|c|c|c|c|c|}
\hline & \multicolumn{4}{|c|}{ P1 (Factor 1) } & \\
\hline $\begin{array}{c}\text { Course of } \\
\text { study }\end{array}$ & $\begin{array}{c}1 \\
\text { «overall } \\
\text { positive» }\end{array}$ & $\begin{array}{c}\text { Pearson's Chi Square: 9,62; } \mathrm{p}=0,14, \alpha=0,05 \\
\text { «I appreciate it, } \\
\text { but note the } \\
\text { flaws» }\end{array}$ & $\begin{array}{c}3 \\
\text { «I assess it } \\
\text { negatively, but note } \\
\text { a number of } \\
\text { advantages» }\end{array}$ & $\begin{array}{c}4 \\
\text { «overall } \\
\text { negative» }\end{array}$ & Total \\
\hline 1 & 6 & 19 & 20 & 10 & 55 \\
\hline 2 & 7 & 25 & 26 & 15 & 73 \\
\hline 3 & 8 & 34 & 27 & 11 & 80 \\
\hline 4 & 8 & 30 & 25 & 11 & 74 \\
\hline Total & 29 & 108 & 98 & 47 & 282 \\
\hline
\end{tabular}

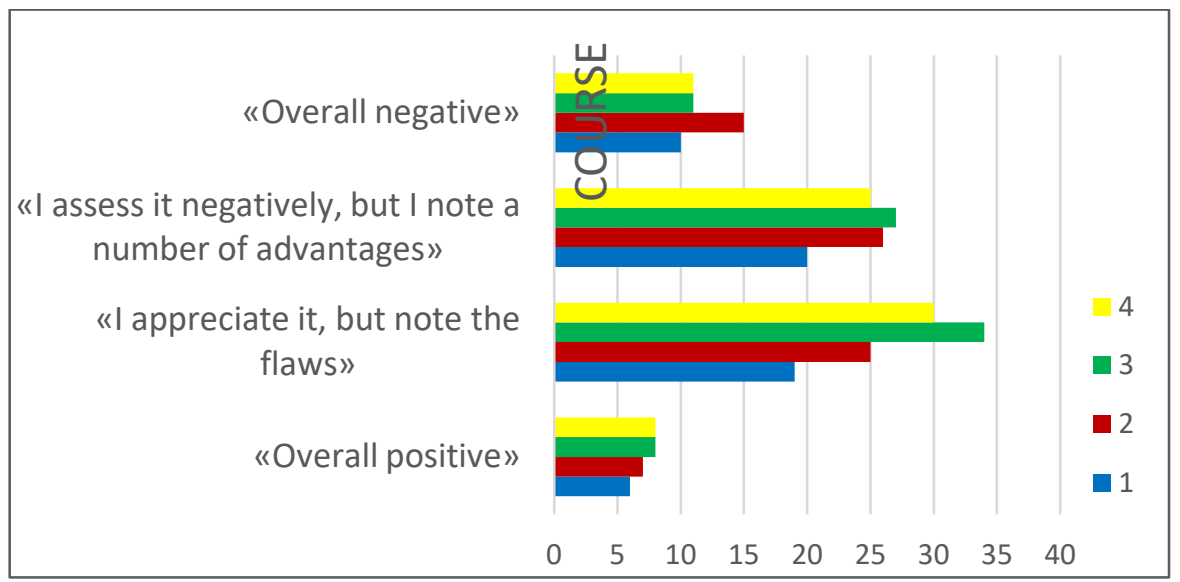

Fig. 1 - Distribution of results of questionnaire on years of schooling.

The data in Table 4 (Fig. 1) show that in the groups of respondents of the 3-4th year of study, the most common occurrence is "I assess positively, but note shortcomings" in relation to the presence of the institution of inclusive education. Among respondents of 1-2 courses of study, the most often present option is "I assess negatively, but note a number of advantags". A chi-square test indicates a slight difference in the level of voters' confidence depending on the course of study $(p=0.14>\alpha=0.05)$.

The analysis of the complete answers has been done. It should be noted that "inclusive education" is familiar to more than $1 \backslash 3$ of respondents. They gave right, full definition and take people with disabilities positively. $2 \backslash 3$ of respondents either don't think about this question or don't understand the core and positive moments of such education. The results obtained show the degree of readiness of our society to live and work in an inclusive format. 
The outcome showed that in a whole the students have a positive attitude to people with disabilities and regard the study together with them as a rationale one. The respondents who didn't come across such individuals are undecided to judge their own attitude to such people. The youth doesn't have clear outlook to this issue and this lacuna is gradually filled by obtaining personal life experience, therefore it is important to give the youth some kind of scientific pedagogical base for their axiological and cognitive components in the system of social reference points.

\section{Perspectives of inclusive education in the modern information society}

Consideration and conclusions: inclusive education and its truthful social and philosophical understanding, as well as the opportunities, given by new IT, interactive and distance study, give a chance to the disabled children. Integrity of such methods and there comprehension opens a great variety of opportunities for all children, especially for those who have any diversities.

The formation of the modern information society presupposes gradual evolution of social structure aimed at the increase of the level of correspondence to the basic necessities of people. Moreover, all members of society have needs, regardless of their physical condition and their health. Due to the intensive scientific and technical progress in some countries the problem of providing population with vital resources was solved and the development of the society followed suit of cultural enrichment, formation of the developed recreational sphere, making of the educational system. Information society gives to some people a wide range of opportunities for personal development and inclusion into socio-communicative environment.

Herewith, taking into consideration a wide set of opportunities of the development and innate into the structure of social interactions moment of the social mobility the main factor defining the way of the development of a certain person is primarily a set of his personal soft skills that includes the state of health, the level of lifeware and physical capacity, moral and professional development and motivation to the implementation of vigorous social activity.

However this statement is fair only concerning those members of the society the state of whom is within the limits of psychophysiological norms. People with physical, sensor and intellectual disabilities primarily possess less competitive features in the social environment, and the process of the personal formation demands taking much more efforts compared to the development of a healthy person. Herewith, in terms when the achievement of the results easy available to all people around presents significant problem and the society gives patronage to the disabled people isolating them from the aggressive outside environment there comes out all prerequisites to the decrease of the level of motivation for the development. As a result not only the health state but the character of the involvement into the social environment define the absence of the favourable conditions for the personal formation of disabled people.

Consequently, realized social processes and technologies disclose incapacity in the question of organization of comfortable conditions of social existence for disabled people inherent part of which (on the level of process and consequent supplement of results) is education.

One of the possible ways out of the current situation is the implementation of reforms in the educational sphere connected with the formation of comfortable development environment for disabled children corresponding to their opportunities and contributing to their development on the basis of existing educational system. 
Taking into consideration that the question is about a wide range of tendencies of development, from a set of academic knowledge and professional skills to the development of communicative skills and common social involvement the formation of such educational environment that from the childhood contributes to the development of social involvement of children with disabilities is needed. In modern pedagogic theory one of the most advanced models in current question is the inclusive education connected with the initial inclusion of the disabled children into classrooms in which together with disabled children healthy children are trained. That can contribute to the copability of social exclusion of disabled children, formation of the important set of the communicative skills and the increase of growth of motivation connected with necessity of copability of the limitedness of the development connected with the state of health. The condition of the modern information space of education, implementation of distant approaches, computerization of education that makes disabled children equal in the virtual educational process also contribute to the development of the current approach that gives real results.

The main problem is that the inclusive education doesn't resolve into simple inclusion of disabled children into the educational process. The recompense of difficulties connected with the state of health and the control of psychological climate in group, change of the conditions of professional activity of teachers and solution of the wide range of problems connected with the differences in terms of training of disabled children and healthy ones are needed.

The relevance of the analytical treatment of the current problem is connected both with the necessity of providing disabled children with worthy development conditions and with the risk of inappropriate technologies of realization of the inclusive education model in terms of high orientation of society on its implementation and herewith in terms of low elaborateness of the system aspect of the problem considering conditions and consequences of the implementation of the inclusive education.

\section{Conclusion}

Analyzing basic approaches to the providing people with disabilities with appropriate conditions for getting education and further inclusion into active social life the following principal positions can be distinguished:

- $\quad$ education in specialized foster homes formed with the consideration of abilities of disabled children and representing closed social environment differentiated from general educational institutions where the healthy children are trained;

- $\quad$ home schooling presupposing individual approach to every disabled child. Current approach is well realized by the distant technologies of the educational process;

inclusive education presupposing active inclusion of disabled children into the social school life (further in higher educational institutions) where educational activity is performed in line with general academic program but the moment of individual approach to disabled children is realized.

Further we'll observe advantages and disadvantages of every given approach one by one.

Peculiarity of education in specialized foster homes is the presence in the teaching staff specialists oriented on the work with disabled children. It is referred both to knowledge of specific correctional methods and deep psychological elaborateness of the question. In Soviet educational system current approach had been prevalent for a long time herewith it was considered that separate education of healthy and disabled children meet interests of the later, contribute to their protection from aggressive outer social environment and also let determine 
academic load in accordance with opportunities of learners. For many families such foster homes were escapes from complex situations due to the fact that they provided round a clock living of a child accompanied by his support and development.

At the same time such approach has significant disadvantages, the principal of which is connected with fixation of self-determination through an ailment, taking by learners of their "special status" on the one hand belittling person's dignity and on the other hand determining necessity of outsider's support. Ultimately social paradigm of disabled children's protection bringing the process of patronage to the level of isolation leads to the decrease of the inclusion of disabled children into social life and to the formation of dependency social attitude of disabled people both in them and in members of the society in common. As a result, there can be reported low level of socialization, inadaptability to the external social conditions, difficulty in further social development and its cessation. In this case there is not the solution of the problem but its conservation that can't help affecting final results. In fact, as a result of education at foster homes disabled children get even bigger gap which is emerged both on the communicative level and on the level of ways of participation in main spheres of public life comparably to healthy children.

One of the most common ways of solution of problem of disabilities in learners is the realization of a model of home schooling when the responsibility for educational -bringingup process is taken by children's parents and teachers performing individual work with a child. Despite the fact that individual approach can be significantly paid off such kind of education has some disadvantages. The main disadvantage here is the secluded character of child's social life, absence of opportunities of his effective socialization which is actively performed in class groups of educational institutions. One more important moment is connected with the absence of communal grounds for qualitative educational activity connected with competitive effect, self affirmation through the success in educational activity and the presence of high hurdle set by other learners. Despite the fact that the achievement of academic tasks for disabled children represents much bigger difficulty in comparison with other learners the moment of motivation to education among disabled children studying equally with other children in educational institutions is significantly higher than during home schooling in the comfort zone oriented at moral support and recompense (as well as omission and de-actualization) of disadvantages of the development. Besides, significant difficulty can be observed in the current situation when the lack of specialists in the educational sphere leads to the physical impossibility of complete providing of the educational process for all children trained at home. The transfer of personal contact with a teacher into the frame of distant education is not the way out.

New technologies of education in the virtual educational world are useful for everyone, but for healthy children it is one of the ways of getting knowledge and for the disabled children it is a forced necessity. As a result, significant part of work is laid on parents who are not possessing pedagogic qualification. Despite the fact that the given above approach has a long history of use, technically and technologically well-equipped, it is obvious that its efficiency is rather low and ultimate costs have negative character.

As to the paradigm of the inclusive education it should be noted that currently it represents one of the most advanced approaches aimed at the formation of basic necessary conditions for the effective inclusion of the disabled people into social life. The premise of the inclusive education is not just a concept of necessity of the inclusion of disabled children into the educational process together with other children. The inclusive education is primarily a social strategy aimed at the effective inclusion of disabled people into the social life that with teachers' control will allow them to pass safely the way of preparation to the interaction with society. One of the main principles compiling the inclusive approach is the statement about the necessity of exclusion of the discriminative practices from the structure of the current system of education. There is a flat line: due to the fact that direct guardianship of the disabled 
children has negative effects the inclusive education presupposes not the formation of liberal attitude to a child with disabilities but the use of individually chosen methods aimed at fulfilling his potential. Therefore, there is a realization of the moment of fair management of educational process in which both common interest of class and interests of a child possessing problems with lifeware, physical and sensor opportunities are taken into consideration.

Practice of organization of the inclusive education traces its roots in the developed Eastern countries - the USA, Germany, Denmark, Norway and so on [5]. Generalizing experience of the formation of educational institutions with the realization of principles of the inclusive education it should be noted that there exist a range of serious problems connected with the implementation of current practice. We'll observe them one by one.

Firstly, such organization of the educational-bringing-up process in which individual attitude to the disabled children is realized without detriment to the rest of the educational group represents a big difficulty. As a rule one of two scenarios is realized- either "pulling up" of a disabled child is performed by distracting teacher's attention from the rest of the group or a child with disabilities is to study on standard terms that results in low educational figures which significantly weaken self esteem and block motivation to the continuation of the study. Current practice is universally rated both from the position of valuable and objectivistic approaches. As the practice of the inclusive education in Denmark shows the greatest efficiency can be observed within a framework of educational course of the primary school while in senior classes there observed an aggravating problem in the speed of assimilation of the material [5]. One of the important factors in this case is the class size where the disabled children are trained. According to the researches in the field of organization of the inclusive education the optimal moment is the reduction of classes' sizes that include disabled children up to $10-15$ persons that allows performing sufficiently intensive work with an unhealthy child without detriment to other children [4].

One more significant problem is the qualification of teachers. To train a child with disabilities it is necessary to possess a significant set of special knowledge and skills that allow performing proper correction of the educational process [6]. In this regard the realization of principles of the inclusive education presupposes the appearance of new standards of educational activity that can affect the character of the professional training of future teachers.

We can't help but take into consideration the fact that in Russia even the organization of the educational process for healthy children at the current class size represents a big problem that is connected with common issue of deficiency of the teaching staff of general academic schools. Since the inclusive education presupposes the division of training groups we face a sharp necessity in recruiting working staff to the teaching process at schools. This, in turn, demands the increase of status value of teacher's profession as in current conditions teachers are more enthusiasts than bearers of well-paid prestigious profession.

Together with the given above problems significant meaning is given to such technical moments as character of the design of school buildings (that is connected with difficulty of ascending of some disabled children), organization of on-site roads to school to the disabled children, provision of information about the possibility of the inclusion into the educational process at schools that already have a practice of the inclusive education.

An important aspect of the inclusive approach and its technical realization is school technical equipping with computers, interactive boards, high speed internet, and modern software. Communication "teacher-pupil" can be partially transferred in the information field, in new-style that allows saving time of a teacher and giving it to those really requiring it.

The pointed above moments bear technical character, however, they represent those obstacles that don't allow solving the problem of the organization of educational opportunities for the disabled children at once. However, besides them significant meaning 
is given to the communicative aspect and, in particular, risks connected with the inclusion of a special needs child into a child group. Currently bulling is becoming one of the serious problems in the educational institutions- targeted manhunt when the member of a group who differs from classmates in any characteristic (communication manner, appearance, ethnic background and so on) becomes the object of it [9]. Bulling represents the realization of the destructive model of self affirmation by means of belittling dignity of another person and commonly it is referred to those who are socially vulnerable [9]. In these terms disabled children are in a risk group and therefore the process of the inclusive education is associated with significant risks. Due to this the necessity of organization of conditions for getting education by disabled children presupposes not only the formation of measures on the institutional level but the creation of prerequisites for the formation of advantageous psychological climate in groups. And, it is referred, on one hand, to the increase of control of non-formal aspect of intra-group interaction, and, on the other hand, to the significance of educational activity aimed at implanting of constructive models of group interaction.

Summarizing the above it should be noted that the inclusive education represents overwhelmingly important step in the development of the society, and in the context of necessity of the inclusion of the disabled children into active social life this step is necessary. However, its realization is connected with solution of a wide range of problems that determine high level of risks for the disabled children and the decrease of quality of the educational process on the whole (in terms of disregarding these problems). The formation of the inclusive education is not just a reform of the educational structure and the implementation of progressive, high technology educational methods to some schools. The formation of the effective system of the inclusive education demands a wide complex of social and technical reformations. The refore it is significantly important not to turn the inclusive education into a non-figurative social measure, fiction that can cause significant psychological damage to the disabled children.

Informatization of education with the consideration of communicative and adaptive problems of the disabled children can become an important factor of the implementation of the inclusive education into modern school [27]. The creation of a new information-oriented society with the consideration of needs of some part of this society with the individual peculiarities of the development is a solvable task in the time of high technologies, intelligent approaches of the formation of information systems and modern opportunities of robotic technologies.

\section{References}

1. G. R. Ziatdinova, Socialization of disabled children by means of social and cultural activities, 244 (2011)

2. A.Ya. Chirgina, Inclusive education of disabled children with severe physical disabilities as a factor in their social integration, 147 (2011)

3. N. A. Medova, Model of inclusive education in the conditions of the municipal educational system (2013)

4. N. A. Buravleva, N. K. Grickevich, N. V. Iglovskaya, Inclusive Education: First Experience and Problems, Science Vector of Togliatinsk State University, Series: Pedagogy, Psychology, 3, 60-63 (2011)

5. L. K. Kurmysheva, Inclusive education: foreign experience, Siberian pedagogical J., 9, 221-224 (2012)

6. A. D. Goneev, E. G. Samarceva, The problem of preparing future teachers for the implementation of inclusive education for children with special educational needs, Scientific notes of OSU, Series: Humanities and Social Sciences, 4, 341-345 (2013) 
7. M. J Guralnick, R. T. Connor, M. A. Hammond, J. M. Gottman, K. Kinnish, Immediate effects of mainstreamed settings on the social interactions and social integration of preschool children, American J. On Mental Retardation, 100 (4), 359-377 (1996)

8. K. Kavale, S. Forness, History, rhetoric and realty, Analysis of inclusion debate, Remedial and Special Eduction, 21 (5) (2000)

9. A. Dyson, Inclusion and inclusions: theories and discourses in inclusive education, 3653 (World Yearbook of Education 1999, Inclusive Education, New York: Routledge, 1999)

10. R. Park, Assimilation, Introduction to the Science of Sociology, 734-739 (1969)

11. G. Thoma, P. Walker, J. Webb, The Making of the Inclusive School (London and New York: Routledge Falmer, 1998)

12. E. B. Wright, Full Inclusion of Children with Disabilities in the Regular Classroom: Is It the Only Answer?, Social work in Education, 21, 1 (1990)

13. V. R. Petrosyanc, Bullying in the modern educational environment, Bulletin of TSPU, 6, 151-154 (2011)

14. V. R. Petrosyanc, Psychological characteristics of high school students, participants in bullying in the educational environment, and their resilience, 210 (2011)

15. I. L. Sizova, Sociological theory about the causes of violence at school, Vestnik NNSU, 9 (6-1), 374-380 (2012)

16. G. M. Batsche, H. M. Knoff, Bullies and their victims: Understanding a pervasive problem in the schools, School Psychology Review, 23 (2), 165-174 (1994)

17. K. A. Berthold, J. H. Hoover, Correlates of bullying and victimization among intermediate students in the mid western USA, School Psychology International, 21(1), 65-78 (2000)

18. V. E. Besag, Bullies and Victims in Schools (Milton Keynes: Open University Press, 1989)

19. K. A. Dodge, The structure and function of reactive and proactive aggression, The development and treatment of childhood aggression, 201-216, (Hillsdale, NJ: Lawetance Erlbaum 1991)

20. K. A. Dodge, N.R. Crick, Social information-processing bases of aggressive behavior in children, Personality and Social Psychology Bulletin, 16 (1), 8-22 (1990)

21. R. Q. Bell, A reinterpretation of the direction of effects in studies of socialization, Psychological review, 75 (1968)

22. E. H. Erikson, Childhood and society (1985)

23. H. Gardner, The arts of human development (New York: Wiley 1973)

24. M. B. Karnes, Alternative models for delivering service to young handicapped children, Theory into practice (1972)

25. E. E. Maccoby, Socialization in the context of the family: parent-child interaction, In Handbook of child psychology: socialization, personality, and social development (New York, 1983)

26. S. F. Stanley, Family education to enhance the moral atmosphere of the family and the moral development of adolescents, Journal of Counseling Psychology, 25 (1978)

27. M. E. Beglaryan, E. A. Pichkurenko, Innovative educational methods in pedagogy, Society: sociology, psychology, pedagogy, 6 (24), 105-107 (2015) 